International

Archives of Allergy

and Immunology

\section{Experimental Immunology - Commentary}

Int Arch Allergy Immunol 2021;182:489-495

DOI: $10.1159 / 000513538$
Received: November 13, 2020 Accepted: November 20, 2020

Published online: December 22, 2020

\title{
Spices to Control COVID-19 Symptoms: Yes, but Not Only...
}

\author{
Jean Bousquet ${ }^{a, b}$ Wienczyslawa Czarlewski ${ }^{c, d}$ Torsten Zuberbier ${ }^{a}$ Joaquim Mullol ${ }^{\mathrm{e}}$ \\ Hubert Blain ${ }^{f}$ Jean-Paul Cristolg ${ }^{g}$ Rafael De La Torre ${ }^{\text {h }}$ Vincent Le Moing ${ }^{k}$ \\ Nieves Pizarro Lozano ${ }^{\mathrm{i}, \mathrm{O}}$ Anna Bedbrook ${ }^{\mathrm{b}, \mathrm{d}}$ loana Agachel Cezmi A. Akdis ${ }^{\mathrm{m}}$ \\ G. Walter Canonica ${ }^{n}$ Alvaro A. Cruz $^{\circ}$ Alessandro Fiocchi ${ }^{p}$ Joao A. Fonseca ${ }^{q}$ \\ Susana Fonsecar ${ }^{r}$ Bilun Gemicioğlus ${ }^{\text {Tari Haahtela }}{ }^{t}$ Guido laccarino $^{u, P}$ \\ Juan Carlos Ivancevich ${ }^{v}$ Marek Jutel $^{\mathrm{w}}$ Ludger Klimek $^{\mathrm{x}}$ Piotr Kuna ${ }^{\mathrm{y}}$ \\ Désirée E. Larenas-Linnemann ${ }^{z}$ Erik Melén ${ }^{A}$ Yoshitaka Okamoto ${ }^{B}$ \\ Nikolaos G. Papadopoulos ${ }^{C}$ D Oliver Pfaar $^{E}$ Jacques Reynes ${ }^{k} \quad$ Yves Rolland $^{F}$
}

Philip W. Rouadi ${ }^{G}$ Boleslaw Samolinski ${ }^{H}$ Aziz Sheikh' Sanna Toppila-Salmi ${ }^{t}$ Arunas Valiulis ${ }^{J}$

Hak-Jong Choi ${ }^{K}$ Hyun Ju Kim ${ }^{\mathrm{L}}$ Josep M. Anto ${ }^{\mathrm{i}, \mathrm{j}, \mathrm{M}, \mathrm{N}}$

aDepartment of Dermatology and Allergy, Charité Universitätsmedizin Berlin, Humboldt-Universität zu Berlin, and Berlin Institute of Health, Comprehensive Allergy Center, Berlin, Germany; ${ }^{b}$ University hospital and MACVIA France, Montpellier, France; ${ }^{c}$ Medical Consulting Czarlewski, Levallois, France; ${ }^{\mathrm{d}}$ MASK-air, Montpellier, France; ${ }^{\mathrm{e}}$ Rhinology Unit \& Smell Clinic, ENT Department, Hospital Clinic-Clinical \& Experimental Respiratory Immunoallergy, IDIBAPS, CIBERES, Universitat de Barcelona, Barcelona, Spain; 'Department of Geriatrics, Montpellier University Hospital, Montpellier, France; 9 Laboratoire de Biochimie et Hormonologie, PhyMedExp, Université de Montpellier, INSERM, CNRS, CHU de Montpellier, Montpellier, France; hCIBER Fisiopatologia de la Obesidad y Nutrición (CIBEROBN), Madrid, Spain; 'IMIM (Hospital del Mar Research Institute), Barcelona, Spain; JUniversitat Pompeu Fabra (UPF), Barcelona, Spain; ' Maladies Infectieuses et Tropicales, CHU, Montpellier, France; 'Faculty of Medicine, Transylvania University, Brasov, Romania; 'mSwiss Institute of Allergy and Asthma Research (SIAF), University of Zurich-Christine

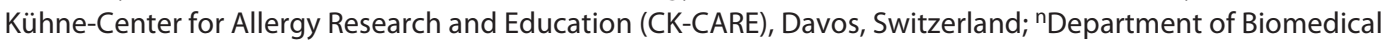
Sciences, Personalized Medicine, Asthma and Allergy, Humanitas Clinical and Research Center IRCCS, Humanitas University, Pieve Emanuele, Italy; ${ }^{\circ}$ Fundação ProAR, Federal University of Bahia and GARD/WHO Planning Group, Salvador, Brazil; ${ }^{P}$ Division of Allergy, Department of Pediatric Medicine-The Bambino Gesù Children's Research Hospital Holy see, Rome, Italy; ${ }^{9}$ CINTESIS, Center for Research in Health Technologies and Information Systems, Faculdade de Medicina da Universidade do Porto, Porto, Portugal and MEDIDA, Lda, Porto, Portugal; 'GreenUPorto-Sustainable Agrifood Production Research Centre, DGAOT, Faculty of Sciences, University of Porto, Campus de Vairão, Vila do Conde, Portugal; 's Department of Pulmonary Diseases, Istanbul University-Cerrahpasa, Cerrahpasa Faculty of Medicine, Istanbul, Turkey; ${ }^{\text {TS}}$ Skin and Allergy Hospital, Helsinki University Hospital, and University of Helsinki, Helsinki, Finland; "Department of Advanced Biomedical Sciences, Federico II University, Napoli, Italy; vServicio de Alergia e Immunologia, Clinica Santa Isabel, Buenos Aires, Argentina; wDepartment of Clinical Immunology, Wrocław Medical University and ALL-MED Medical Research Institute, Wrocław, Poland; ${ }^{x}$ Center for Rhinology and Allergology, Wiesbaden, Germany; ' ${ }^{2}$ ivision of Internal Medicine, Asthma and Allergy, Barlicki University Hospital, Medical University of Lodz, Lodz, Poland; ' Center of Excellence in Asthma and Allergy, Médica Sur Clinical Foundation and Hospital, Mexico City, Mexico; ${ }^{A}$ Institute of Environmental Medicine, Karolinska Institutet and Sachs' Children's Hospital, Stockholm, Sweden;

Edited by: H.-U. Simon, Bern.

karger@karger.com

www.karger.com/iaa

(C) 2020 S. Karger AG, Basel

Karger'
Jean Bousquet

Department of Allergology, Macvia France

273 avenue d'Occitanie

FR-34090 Montpellier (France)

jean.bousquet@orange.fr 
${ }^{B}$ Department of Otorhinolaryngology, Chiba University Hospital, Chiba, Japan; CDivision of Infection, Allergy Department, Immunity \& Respiratory Medicine, Royal Manchester Children's Hospital, University of Manchester, Manchester, UK; ${ }^{D}$ 2nd Pediatric Clinic, Athens General Children's Hospital "P\&A Kyriakou," University of Athens, Athens, Greece; EDepartment of Otorhinolaryngology, Head and Neck Surgery, Section of Rhinology and Allergy,

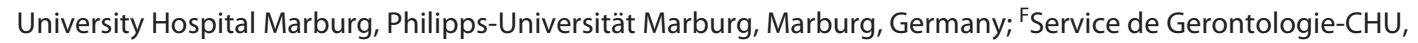
Toulouse, France; GDepartment of Otolaryngology-Head and Neck Surgery, Eye and Ear University Hospital, Beirut, Lebanon; ${ }^{H}$ Department of Prevention of Environmental Hazards and Allergology, Medical University of Warsaw, Warsaw, Poland; 'The Usher Institute of Population Health Sciences and Informatics, The University of Edinburgh, Edinburgh, UK; 'Vilnius University Faculty of Medicine, Institute of Clinical Medicine \& Institute of Health Sciences, Vilnius, Lithuania; KMicrobiology and Functionality Research Group, Research and Development Division, World Institute of Kimchi, Gwangju, South Korea; LSME Service Department, Strategy and Planning Division, World Institute of Kimchi, Gwangju, South Korea; ${ }^{M}$ CIBER Epidemiología y Salud Pública (CIBERESP), Barcelona, Spain; NISGlobAL, Barcelona, Centre for Research in Environmental Epidemiology (CREAL), Barcelona, Spain; ${ }^{\circ}$ Autonomous

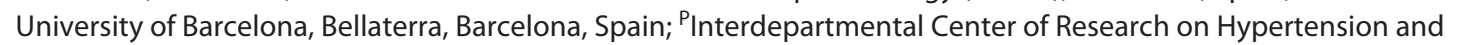
Related Conditions CIRIAPA, Federico II University, Napoli, Italy

\section{Keywords}

Nuclear factor (erythroid-derived 2)-like 2 - Transient receptor potential ankyrin 1 - Transient receptor potential vanillin 1 - COVID-19. Spices · Fermented vegetables

\section{Abstract}

There are large country variations in COVID-19 death rates that may be partly explained by diet. Many countries with low COVID-19 death rates have a common feature of eating large quantities of fermented vegetables such as cabbage and, in some continents, various spices. Fermented vegetables and spices are agonists of the antioxidant transcription factor nuclear factor (erythroid-derived 2)-like 2 (Nrf2), and spices are transient receptor potential ankyrin 1 and vanillin 1 (TRPA1/V1) agonists. These mechanisms may explain many COVID-19 symptoms and severity. It appears that there is a synergy between Nrf2 and TRPA1/V1 foods that may explain the role of diet in COVID-19. One of the mechanisms of COVID-19 appears to be an oxygen species (ROS)-mediated process in synergy with TRP channels, modulated by Nrf2 pathways. Spicy foods are likely to desensitize TRP channels and act in synergy with exogenous antioxidants that activate the Nrf2 pathway.

(c) 2020 S. Karger AG, Basel

\section{Introduction}

Like most diseases, COVID-19 prevalence, severity, and mortality exhibit large geographical variations which frequently remain unexplained. The COVID-19 epidemic is multifactorial, and factors like climate, population density, social distancing, age, phenotype, obesity, prevalence of noncommunicable diseases, and possibly genetic background are associated with increased incidence and mortality [1]. Diet represents only one of the possible moderating factors of the COVID-19 epidemic [2, 3].

Although there are many pitfalls in analyzing death rates for COVID-19 [3], death rates during the Spring pandemic were low or very low in Central European countries, Eastern Asian countries, many sub-Saharan African countries, the Middle East, India, and Pakistan as well as in Australia and New Zealand. This geographical pattern is very unlikely to be totally due to reporting differences between countries. Some very low death rate settings (but not in Australia or New Zealand) have a common feature of eating large quantities of fermented vegetables such as cabbage [2-4] and, in some continents, various spices [5]. The recent COVID-19 outbreak in Europe and the USA does not appear to exist in many Asian or African countries.

Among the spices with a beneficial effect on human health, allicin, capsaicin, curcumin, gingerol, mustard oil, piperine, and quercetin glucosides are the major ones [6]. Most of them have an antioxidant activity through different mechanisms including the direct or indirect activation of nuclear factor (erythroid-derived 2)-like 2 (Nrf2) [7], and all are TRP (transient receptor potential) agonists. However, spices may interact with SARS-CoV-2 by other mechanisms [8].

Three phases of COVID-19 have been described: (i) a viral infection lasting for 1-2 weeks; (ii) a second phase 


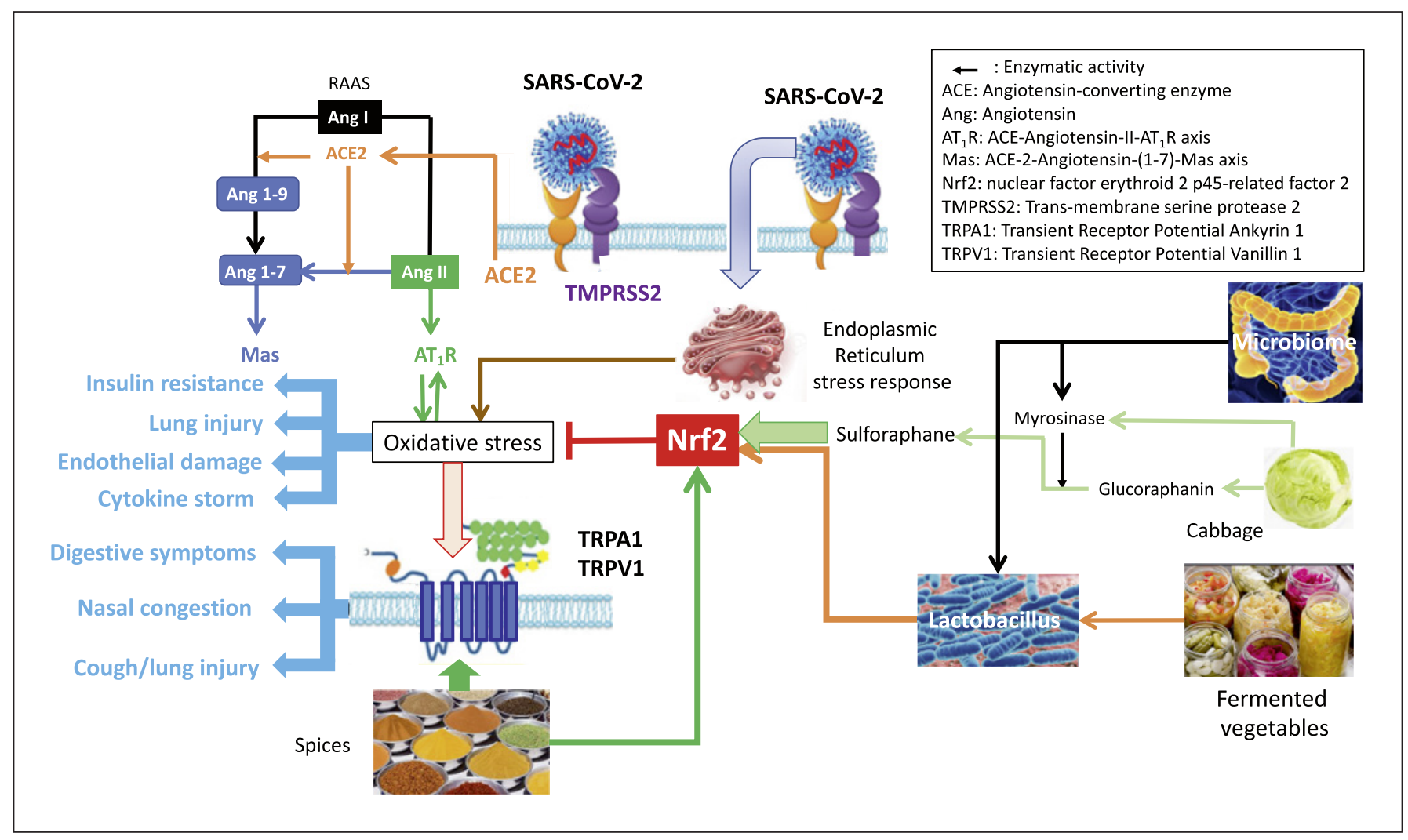

Fig. 1. Interactions between foods and COVID-19. $\leftarrow$, enzymatic activity; ACE, angiotensin-converting enzyme; Ang, angiotensin; $\mathrm{AT}_{1} \mathrm{R}, \mathrm{ACE}$-angiotensin-II-AT ${ }_{1} \mathrm{R}$ axis; Mas, ACE-2-angiotensin-(1-7)-Mas axis; Nrf2, nuclear factor erythroid 2 p45-related factor; TMPRSS2, transmembrane serine protease 2; TRPA1, transient receptor potential ankyrin 1; TRPV1, transient receptor potential vanillin 1; ER, endoplasmic reticulum.

characterized by an intertwined cytokine and oxidative stress storm, independent of infection; and (iii) a recovery phase that may last for some months. Spices may interact differently during these 3 phases.

\section{COVID-19: From Oxidative Stress to TRPs}

\section{Oxidative Stress}

A common denominator in all conditions associated with COVID-19 appears to be the impaired redox homeostasis, responsible for the accumulation of reactive oxygen species (ROS) [9]. Among many others, 2 important mechanisms can be involved $[7,10]$.

The angiotensin-converting enzyme 2 (ACE2) receptor is part of the dual system - the renin-angiotensinsystem - consisting of an ACE-Angiotensin-II-AT $\mathrm{R}_{1}$ axis and an ACE-2-Angiotensin-(1-7)-Mas axis. SARSCoV-2 binds to ACE2 and its receptor, and ACE2 down-

Foods with Antioxidant and TRP

Activities in COVID-19 regulation enhances the $\mathrm{AT}_{1} \mathrm{R}$ axis [11] leading to oxidative stress generation [12]. As a result, this is associated with insulin resistance as well as with lung and endothelial damage and cytokine storm, 3 severe outcomes of COVID-19 [13-15] (shown in Fig. 1).

When SARS-CoV-2 enters the cell, it triggers endoplasmic reticulum (ER) stress responses associated with increased oxidative stress and unfolded protein response (UPR) $[16,17]$. As for other viral infections, ER stress and sustained UPR signalling may be major contributors to the pathogenesis of COVID-19 $[18,19]$ (shown in Fig. 1).

Nrf2 is the most potent antioxidant in humans $[20,21]$ and can downregulate the oxidative stress from the $\mathrm{AT}_{1} \mathrm{R}$ axis as well as in the ER [7,22]. In particular, the upregulation of Nrf2 signalling inhibits the overproduction of IL-6, proinflammatory cytokines, and chemokines. It also limits the activation of nuclear factor-kappa $b(\mathrm{NFkB})$. Other transcription factors involved in oxidative stress 
Table 1. Examples of Nrf2, TRPA1, and TRPV1 interacting spices

\begin{tabular}{lllll}
\hline & Foods & Nrf2 & TRPA1 & TRPV1 \\
\hline Allicin & Garlic, leek, onion & & {$[59]$} & {$[59]$} \\
Capsaicin & Red pepper & {$[60,61]$} & {$[62]$} & {$[63]$} \\
Cinnamaldehyde & Cinnamon & {$[64]$} & {$[65]$} & {$[66]$} \\
Curcumin & Turmeric & {$[67,68]$} & {$[69]$} & {$[69]$} \\
Gingerol & Ginger & {$[70]$} & {$[71]$} & {$[72]$} \\
Mustard oil & Mustard seeds & & {$[73]$} & \\
Piperine & Black and long pepper & {$[74]$} & {$[75]$} & {$[76]$} \\
Wasabi & Japanese horseradish & {$[77]$} & {$[78]$} & {$[78]$} \\
\hline
\end{tabular}

Nrf2, nuclear factor (erythroid-derived 2)-like 2; TRPA1, transient receptor potential ankyrin 1; TRPV1, transient receptor potential vanillin 1 .

are activator protein 1 and NFkB. There is an amplification loop in oxidative stress. Excess ROS induces inflammatory cell recruitment under the effect of IL-6, IL-8, and TNF- $\alpha$, the activation of which generates more $\operatorname{ROS}\left(\mathrm{O}_{2}{ }^{-}\right)$ produced in the mitochondria and ER.

\section{Transient Receptor Potential}

The TRP vanilloid 1 (TRPV1) and ankyrin 1 (TRPA1) are members of the TRP superfamily of structurally-related, nonselective cation channels. TRPV1 and TRPA1 are frequently colocalized in sensory neurons and interact to modulate function. They are also expressed in many nonneuronal cells such as vascular smooth muscle, monocytes, lymphocytes, keratinocytes, epithelial cells, and endothelium [23].

TRPA1 induces inflammation, plays a key role in the physiology of almost all organs [24], and exhibits the highest sensitivity of TRPs to oxidants. TRPA1 can be activated by cold, heat, pungent compounds, mechanical stimuli, endogenous signals of inflammation, and oxidative stress [25].

TRPV1, also known as the capsaicin receptor, has a major function in the detection and regulation of body temperature [26]. It can be activated by some endogenous lipid-derived molecules, acidic solutions, pungent chemicals, food ingredients such as capsaicin, and toxins [27]. TRPV1 is a sensor of oxidative stress, but to a lesser extent than TRPA1.

TRPA1 and TRPV1 augment sensory or vagal nerve discharges to evoke several symptoms of COVID-19, including cough, nasal obstruction, pain, vomiting, diarrhea, and, at least partly, sudden and severe loss of smell and taste [24]. The modulation by Nrf2 of TRPA1/V1 is still unclear but suggested from very limited clinical evidence.

\section{Foods Interacting with Nrf2 and TRPs}

Natural compounds derived from plants, vegetables, and fungi and micronutrients or physical exercise can activate Nrf2 [28, 29]. Many foods have antioxidant properties, and many mechanisms may be involved. However, the activation of Nrf2 may be of primary importance [7, 30, 31]. Differences in COVID-19 death rates among countries may partly be associated with Nrf2 and Nrf2-interacting nutrients like spices and raw or fermented vegetables that could reduce COVID-19 severity [2-4] (shown in Table 1). Nrf2-interacting foods and nutrients may rebalance oxidative stress and have a significant effect on COVID-19 severity [4, 32-34]. On the other hand, many Nrf2 medications were found to be toxic as the balance between oxidant/antioxidant is difficult to obtain.

TRPA 1 and TRPV1 can be activated by pungent compounds including many, but not all, Nrf2-interacting nutrients [24]. Spices and aromatic herbs have potent antibacterial and antiviral activities [35-37]. Spices can also interact with many other mechanisms in COVID-19 including the entry of SARS-CoV-2 into the cell and autophagy processes $[7,38]$.

\section{Clinical Data Supporting the Hypothesis}

A few patients have been studied in order to assess their response to foods. Seven COVID-19 patients received either broccoli and paracetamol (submitted, available online) [39] or broccoli with TRPA1/V1 and paracetamol during the first 2 phases of the infection. It was consistently found that these nutrients reduced cough, gastrointestinal symptoms, and nasal symptoms very rapidly (within minutes). Fatigue was usually largely improved $1 \mathrm{~h}$ after ingestion. Loss of smell and taste were mostly unchanged. Pain and headache were inconstantly improved. The effect of the nutrients ranged from 4 to $8 \mathrm{~h}$, after which patients had a reoccurrence of symptoms.

A series of cough-induced challenges were carried out on one of the patients during the recovery phase. Eight double-blind, placebo-controlled challenges showed that broccoli was effective in reducing cough within $10 \mathrm{~min}$ (submitted, available online) [39]. Forty-nine open-label induced cough challenges were subsequently carried out on the same patient. Nutrients with various Nrf2 and TRPA1/V1 agonist activity were used: broccoli (potent Nrf2 agonist and mild TRPA1 activity), berberine (Nrf2 
only), black pepper, curcumin, ginger, green tea, resveratrol, and zinc (potent TRPA1 agonists and variable Nrf2 agonists) as well as red pepper (potent TRPV1 agonist and Nrf2 agonist). Berberine and zinc were not effective. All of the other nutrients except resveratrol were rapidly effective (1-10 $\mathrm{min})$. The effect of TRPA1/V1 agonists disappeared in 1-4 h. Broccoli induced a longer duration of action (5-7 h). The duration of the effect increased to around $10 \mathrm{~h}$ when low doses of TRPA1/V1 agonists were added to low-dose broccoli. Paracetamol low dose (its metabolites, $N$-acetyl- $p$-benzoquinone imine and $p$-benzoquinone, but not paracetamol itself, are TRPA1/TRPV1 agonists [40]) increases the duration of action of the TRPA1/V1-broccoli combinations to over $14 \mathrm{~h}$.

The results of the challenges suggest a rapid short-lasting TRPA1/V1 desensitization (papers submitted and available online $[39,41])$ : (i) the clinical effect found in challenges carried out with curcumin and black pepper, ginger, or green tea (all TRPA1 agonists) and capsaicin (TRPV1 agonist) was extremely rapid; (ii) the duration of action of the compounds was relatively short; (iii) shortlasting and mild episodes of cough were observed during the challenges, suggesting a resensitization-desensitization of receptors; and (iv) gastroesophageal symptoms were experienced when cough reoccurred at the end of the challenges with red and black pepper.

The results of the clinical studies presented herein cannot be taken as formal evidence. However, they have contributed to developing a proof of concept for the hypothesis that combined Nrf2-TRPA1/V1 foods may be beneficial for some COVID-19 symptoms and that there is a synergy between Nrf2 and TRPA1/V1 agonists. Before any conclusion can be drawn and these treatments recommended for COVID-19, the data warrant confirmation. In particular, the benefits of the foods need to be assessed in more severe and/or hospitalized patients through large and properly designed studies with a double-blind, placebo-controlled design. These immediate effects cannot be related to the blockage of the virus entry into the cells or to autophagy [7].

\section{Spices in COVID-19 Control: Yes, but...}

In COVID-19, a rapid desensitization of TRAP1/V1 by spices is likely to reduce disease severity. However, Nrf2 agonists expand the duration of action of spices. Very high doses of spices regularly consumed in Asian or sub-Saharan countries could reduce COVID-19 infection and/or severity. However, in Western countries, except possibly in Hungary, most people usually eat less spicy foods, and doses ingested elsewhere cannot be given rapidly due to side effects (mostly gastrointestinal intolerance). In these countries, it would be advantageous to combine Nrf2-TRP agonists.

In countries where large amounts of spices are eaten, the consumption of fermented vegetables is also high. This is the case for cassava in Africa or many fermented vegetables in Asia. Different types of fermented foods are widely consumed in Eastern Asian countries. Among them, kimchi is the most popular Korean traditional food. Kimchi is prepared by fermenting baechu cabbage with other cruciferous vegetables containing precursors of sulforaphane, the most active natural activator of $\mathrm{Nrf} 2$ [42]. Subingredients such as garlic, ginger, leaf mustard, and red pepper powder are TRPA1/V1 potent agonists [43]. During fermentation, lactic acid bacteria produce biologically active peptides with antioxidant activity [4449] and Nrf2 interaction [50]. In such countries, it is possible that another form of TRP desensitization, "tachyphylaxis," may be important. This is the reduction or disappearance in the response to repeated applications of agonists [51-53].

Nrf2-TRPA1/V1 agonists may have some relevance for the treatment of persistent cough following viral infections [54-56], both in nonallergic rhinitis [57, 58], and also possibly in some symptoms of the common cold. We do however urgently need to go from empiricism to science with appropriate mechanistic and clinical studies.

\section{Conflict of Interest Statement}

The authors have no conflicts of interest to declare.

\section{Funding Sources}

The authors did not receive any funding.

\section{Author Contributions}

J.B. proposed the concept and discussed it with J.M.A., T.Z., and W.C. J.M., H.B., J.P.C., Rdl.T., V.L.M., N.P.L., and A.B. were part of the think tank group. S.C.F. and G.I. discussed the food data, H.J.C. and H.J.K. discussed the kimchi data, and I.A., C.A.A., G.W.C., A.A.C., A.F., J.F., B.G., T.H., J.C.I., M.J., L.K., P.K., D.L.L., E.M., Y.O., N.G.P., O.P., J.R., Y.R., P.P.R., B.S., A.S., S.T.S., and A.V. were requested to comment on the concept and to review the paper. All authors accepted the paper. 


\section{References}

1 Kissler SM, Tedijanto C, Goldstein E, Grad $\mathrm{YH}$, Lipsitch M. Projecting the transmission dynamics of SARS-CoV-2 through the postpandemic period. Science. 2020;368(6493): 860-8.

2 Bousquet J, Czarlewski W, Blain H, Zuberbier T, Anto J. Rapid response: why Germany's case fatality rate seems so low: is nutrition another possibility. BMJ. 2020;369: m1395.https:// www.bmj.com/content/369/bmj.m1395/rr-12.

3 Bousquet J, Anto JM, Anto JM, Iaccarino G, Czarlewski W, Haahtela T, et al. Is diet partly responsible for differences in COVID-19 death rates between and within countries? Clin Transl Allergy. 2020;10(1):16.

4 Bousquet J, Anto JM, Czarlewski W, Haahtela T, Fonseca SC, Iaccarino G, et al. Cabbage and fermented vegetables: from death rate heterogeneity in countries to candidates for mitigation strategies of severe COVID-19. Allergy. 2020.

5 Elsayed Y, Khan NA. Immunity-boosting spices and the novel coronavirus. ACS Chem Neurosci. 2020;11(12):1696-8.

6 Garcia-Casal MN, Pena-Rosas JP, Malave HG. Sauces, spices, and condiments: definitions, potential benefits, consumption patterns, and global markets. Ann N Y Acad Sci. 2016;1379(1):3-16.

7 Bousquet J, Cristol J, Czarlewski W, Anto J, Martineau A, Haahtela T, et al. Nrf2-interacting nutrients and COVID-19: time for research to develop adaptation strategies. Clin Transl Allergy. 2020;10(1):58.

8 Sen D, Debnath P, Debnath B, Bhaumik S, Debnath S. Identification of potential inhibitors of SARS-CoV-2 main protease and spike receptor from 10 important spices through structure-based virtual screening and molecular dynamic study. J Biomol Struct Dyn. 2020:1-22.

9 Silvagno F, Vernone A, Pescarmona GP. The role of glutathione in protecting against the severe inflammatory response triggered by COVID-19. Antioxidants. 2020;9(7):624.

10 Zahedipour F, Hosseini SA, Sathyapalan T, Majeed M, Jamialahmadi T, Al-Rasadi K, et al. Potential effects of curcumin in the treatment of COVID-19 infection. Phytother Res. 2020;34(11):2911-20.

11 Sarzani R, Giulietti F, Di Pentima C, Giordano P, Spannella F. Disequilibrium between the classic renin-angiotensin system and its opposing arm in SARS-COV-2 related lung injury. Am J Physiol Lung Cell Mol Physiol. 2020;319(2):L325-L36.

12 Wen H, Gwathmey JK, Xie LH. Oxidative stress-mediated effects of angiotensin II in the cardiovascular system. World J Hypertens. 2012;2(4):34-44.

13 Bousquet J, Anto J, Czarlewski W, Haahtela T, Fonseca S, Iaccarino G, et al. Sulforaphane: from death rate heterogeneity in countries to candidate for prevention of severe COVID-19 Allergy. 2020.
14 Ren H, Yang Y, Wang F, Yan Y, Shi X, Dong $\mathrm{K}$, et al. Association of the insulin resistance marker TyG index with the severity and mortality of COVID-19. Cardiovasc Diabetol. 2020;19(1):58.

15 Dalan R, Bornstein SR, El-Armouche A, Rodionov RN, Markov A, Wielockx B, et al. The ACE-2 in COVID-19: foe or friend? Horm Metab Res. 2020;52(5):257-63.

16 Banerjee A, Czinn SJ, Reiter RJ, Blanchard TG. Crosstalk between endoplasmic reticulum stress and anti-viral activities: a novel therapeutic target for COVID-19. Life Sci. 2020;255:117842.

17 Sureda A, Alizadeh J, Nabavi SF, BerindanNeagoe I, Cismaru CA, Jeandet P, et al. Endoplasmic reticulum as a potential therapeutic target for covid-19 infection management? Eur J Pharmacol. 2020;882:173288.

18 Oakes SA, Papa FR. The role of endoplasmic reticulum stress in human pathology. Annu Rev Pathol. 2015;10:173-94.

19 So JS. Roles of endoplasmic reticulum stress in immune responses. Mol Cells. 2018;41(8): 705-16.

20 Tonelli C, Chio IIC, Tuveson DA. Transcriptional regulation by Nrf2. Antioxid Redox Signal. 2018;29(17):1727-45

21 Yamamoto M, Kensler TW, Motohashi H. The KEAP1-NRF2 system: a thiol-based sensor-effector apparatus for maintaining redox homeostasis. Physiol Rev. 2018;98(3):1169-203.

22 Ahmed SM, Luo L, Namani A, Wang XJ, Tang $\mathrm{X}$. Nrf2 signaling pathway: pivotal roles in inflammation. Biochim Biophys Acta. 2017; 1863(2):585-97.

23 Fernandes ES, Fernandes MA, Keeble JE. The functions of TRPA1 and TRPV1: moving away from sensory nerves. Br J Pharmacol. 2012;166(2):510-21.

24 Talavera K, Startek JB, Alvarez-Collazo J, Boonen B, Alpizar YA, Sanchez A, et al. Mammalian transient receptor potential TRPA1 channels: from structure to disease. Physiol Rev. 2020;100(2):725-803.

25 Kadkova A, Synytsya V, Krusek J, Zimova L, Vlachova V. Molecular basis of TRPA1 regulation in nociceptive neurons. a review. Physiol Res. 2017;66(3):425-39.

26 Zheng W, Wen H. Heat activation mechanism of TRPV1: new insights from molecular dynamics simulation. Temperature. 2019; 6(2):120-31.

27 Bevan S, Quallo T, Andersson DA. Trpv1. Handb Exp Pharmacol. 2014;222:207-45.

28 Jimenez-Osorio AS, Gonzalez-Reyes S, Pedraza-Chaverri J. Natural Nrf2 activators in diabetes. Clin Chim Acta. 2015;448:182-92.

29 Pall ML, Levine S. Nrf2, a master regulator of detoxification and also antioxidant, anti-inflammatory and other cytoprotective mechanisms, is raised by health promoting factors. Sheng Li Xue Bao. 2015;67(1):1-18.
30 Martinez-Huelamo M, Rodriguez-Morato J, Boronat A, de la Torre R. Modulation of Nrf2 by olive oil and wine polyphenols and neuroprotection. Antioxidants. 2017;6(4):73.

31 Martucci M, Ostan R, Biondi F, Bellavista E, Fabbri C, Bertarelli C, et al. Mediterranean diet and inflammaging within the hormesis paradigm. Nutr Rev. 2017;75(6):442-55.

32 Cuadrado A, Pajares M, Benito C, JimenezVillegas J, Escoll M, Fernandez-Gines R, et al. Can activation of NRF2 be a strategy against COVID-19? Trends Pharmacol Sci. 2020; 41(9):598-610.

33 Hassan SM, Jawad MJ, Ahjel SW, Singh RB, Singh J, Awad SM, et al. The Nrf2 activator (DMF) and COVID-19: is there a possible role? Med Arch. 2020;74(2):134-8.

34 McCord JM, Hybertson BM, Cota-Gomez A, Gao B. Nrf2 activator PB125(R) as a potential therapeutic agent against COVID-19. bioRxiv. 2020.

35 Viuda-Martos M, Ruiz-Navajas Y, Fernández-López J, Pérez-Alvarez JA. Spices as functional foods. Crit Rev Food Sci Nutr. 2011; 51(1):13-28.

36 Jessica Elizabeth T, Gassara F, Kouassi AP, Brar SK, Belkacemi K. Spice use in food: properties and benefits. Crit Rev Food Sci Nutr. 2017;57(6):1078-88.

37 Boukhatem MN, Setzer WN. Aromatic herbs, medicinal plant-derived essential oils, and phytochemical extracts as potential therapies for coronaviruses: future perspectives. Plants. 2020;9(6):800.

38 Soni VK, Mehta A, Ratre YK, Tiwari AK, Amit A, Singh RP, et al. Curcumin, a traditional spice component, can hold the promise against COVID-19? Eur J Pharmacol. 2020; 886:173551.

39 Bousquet J, Le-Moing V, Blain H, Czarlewski W, Zuberbier T, de-la-Torre R, et al. Efficacy of broccoli and glucoraphanin in COVID-19: from hypothesis to proof-of-concept with three experimental clinical cases. World Allergy Organ J. 2020. : http://wwwga2lennet/ PDF/06Clinical\%20cases-broccolipdf.

40 Andersson DA, Gentry C, Moss S, Bevan S. Transient receptor potential A1 is a sensory receptor for multiple products of oxidative stress. J Neurosci. 2008;28(10):2485-94.

41 Bousquet J, Czarlewski W, Zuberbier T, Mullol J, Blain H, Cristol J, et al. Potential control of COVID-19 symptoms by Nrf2-interacting nutrients with TRPA1 (transient receptor potential ankyrin 1) agonist activity. Clin Transl Allergy. 2020. http://wwwga2lennet.

42 Patra JK, Das G, Paramithiotis S, Shin HS. Kimchi and other widely consumed traditional fermented foods of Korea: a review. Front Microbiol. 2016;7:1493.

43 Park KY, Jeong JK, Lee YE, Daily JW 3rd. Health benefits of kimchi (Korean fermented vegetables) as a probiotic food. J Med Food. 2014;17(1):6-20. 
44 Sanlier N, Gokcen BB, Sezgin AC. Health benefits of fermented foods. Crit Rev Food Sci Nutr. 2019;59(3):506-27.

45 Lavefve L, Marasini D, Carbonero F. Microbial ecology of fermented vegetables and nonalcoholic drinks and current knowledge on their impact on human health. Adv Food Nutr Res. 2019;87:147-85.

46 Melini F, Melini V, Luziatelli F, Ficca AG, Ruzzi M. Health-promoting components in fermented foods: an up-to-date systematic review. Nutrients. 2019;11(5):1189.

47 Azam M, Mohsin M, Ijaz H, Tulain UR, Ashraf MA, Fayyaz A, et al. Review: lactic acid bacteria in traditional fermented Asian foods. Pak J Pharm Sci. 2017;30(5):1803-14.

48 Dimidi E, Cox SR, Rossi M, Whelan K. Fermented foods: definitions and characteristics, impact on the gut microbiota and effects on gastrointestinal health and disease. Nutrients. 2019;11(8):1806

49 Marco ML, Heeney D, Binda S, Cifelli CJ, Cotter PD, Foligné B, et al. Health benefits of fermented foods: microbiota and beyond. Curr Opin Biotechnol. 2017;44:94-102.

50 Kong Y, Olejar KJ, On SLW, Chelikani V. The potential of Lactobacillus spp. For modulating oxidative stress in the gastrointestinal tract. Antioxidants. 2020;9(7):610.

51 Touska F, Marsakova L, Teisinger J, Vlachova V. A "cute" desensitization of TRPV1. Curr Pharm Biotechnol. 2011;12(1):122-9.

52 Tian Q, Hu J, Xie C, Mei K, Pham C, Mo X, et al. Recovery from tachyphylaxis of TRPV1 coincides with recycling to the surface membrane. Proc Natl Acad Sci U S A. 2019; 116(11):5170-5.

53 Sanz-Salvador L, Andrés-Borderia A, FerrerMontiel A, Planells-Cases R. Agonist- and Ca2+-dependent desensitization of TRPV1 channel targets the receptor to lysosomes for degradation. J Biol Chem. 2012;287(23): 19462-71.

54 Abdullah H, Heaney LG, Cosby SL, McGarvey $L P$. Rhinovirus upregulates transient receptor potential channels in a human neuronal cell line: implications for respiratory virus-induced cough reflex sensitivity. Thorax. 2014;69(1):46-54.

55 Omar S, Clarke R, Abdullah H, Brady C, Corry $\mathrm{J}$, Winter $\mathrm{H}$, et al. Respiratory virus infection up-regulates TRPV1, TRPA1 and ASICS3 receptors on airway cells. PLoS One. 2017;12(2):e0171681.

56 Ternesten-Hasseus E, Johansson EL, Millqvist E. Reply to correspondence regarding the paper "Ternesten-Hasséus E, Johansson EL, Millqvist E. Cough reduction using capsaicin. Respir Med. 2015 Jan;109(1):27-37". Respir Med. 2015;109(7):927-37.

57 Van Gerven L, Alpizar YA, Wouters MM, Hox V, Hauben E, Jorissen M, et al. Capsaicin treatment reduces nasal hyperreactivity and transient receptor potential cation channel subfamily V, receptor 1 (TRPV1) overexpression in patients with idiopathic rhinitis. $\mathrm{J} \mathrm{Al}$ lergy Clin Immunol. 2014;133(5):1332-3.

58 Gevorgyan A, Segboer C, Gorissen R, van Drunen CM, Fokkens W. Capsaicin for nonallergic rhinitis. Cochrane Database Syst Rev. 2015(7):CD010591.

59 Ogawa N, Kurokawa T, Mori Y. Sensing of redox status by TRP channels. Cell Calcium. 2016;60(2):115-22.

60 Joung EJ, Li MH, Lee HG, Somparn N, Jung YS, Na HK, et al. Capsaicin induces heme oxygenase-1 expression in HepG2 cells via activation of PI3K-Nrf2 signaling: NAD(P) $\mathrm{H}$ : quinone oxidoreductase as a potential target. Antioxid Redox Signal. 2007;9(12): 2087-98.

61 Srinivasan K. Biological activities of red pepper (Capsicum annuum) and its pungent principle capsaicin: a review. Crit Rev Food Sci Nutr. 2016;56(9):1488-500.

62 Moran MM, Szallasi A. Targeting nociceptive transient receptor potential channels to treat chronic pain: current state of the field. $\mathrm{Br} J$ Pharmacol. 2018;175(12):2185-203.

63 Yang F, Zheng J. Understand spiciness: mechanism of TRPV1 channel activation by capsaicin. Protein Cell. 2017;8(3):169-77.

64 Furue M, Fuyuno Y, Mitoma C, Uchi H, Tsuji G. Therapeutic agents with AHR inhibiting and NRF2 activating activity for managing chloracne. Antioxidants. 2018;7(7):90.

65 Zhu R, Liu H, Liu C, Wang L, Ma R, Chen B, et al. Cinnamaldehyde in diabetes: a review of pharmacology, pharmacokinetics and safety. Pharmacol Res. 2017;122:78-89.

66 Watanabe T, Terada Y. Food compounds activating thermosensitive TRP channels in Asian herbal and medicinal foods. J Nutr Sci Vitaminol. 2015;61(Suppl):S86-8.

67 Malavolta M, Bracci M, Santarelli L, Sayeed MA, Pierpaoli E, Giacconi R, et al. Inducers of senescence,toxic compounds, and senolytics: the multiple faces of Nrf2-activating phytochemicals in cancer adjuvant therapy. Mediators Inflamm. 2018;2018:4159013.

68 Patel SS, Acharya A, Ray RS, Agrawal R, Raghuwanshi R, Jain P. Cellular and molecular mechanisms of curcumin in prevention and treatment of disease. Crit Rev Food Sci Nutr. 2020;60(6):887-939.

69 Nalli M, Ortar G, Schiano Moriello A, Di Marzo V, De Petrocellis L. Effects of curcumin and curcumin analogues on TRP channels. Fitoterapia. 2017;122:126-31.

70 de Lima RMT, Dos Reis AC, de Menezes APM, Santos JVO, Filho JWGO, Ferreira JRO, et al. Protective and therapeutic potential of ginger (Zingiber officinale) extract and [6]-gingerol in cancer: a comprehensive review. Phytother Res. 2018;32(10):1885-907.

71 Yang MQ, Ye LL, Liu XL, Qi XM, Lv JD, Wang $\mathrm{G}$, et al. Gingerol activates noxious cold ion channel TRPA1 in gastrointestinal tract. Chin J Nat Med. 2016;14(6):434-40.

72 Yin Y, Dong Y, Vu S, Yang F, Yarov-Yarovoy $\mathrm{V}$, Tian Y, et al. Structural mechanisms underlying activation of TRPV1 channels by pungent compounds in gingers. Br J Pharmacol. 2019;176(17):3364-77.

73 Guimaraes MZP, Jordt SE. TRPA1: a sensory channel of many talents. In: Liedtke WB, Heller S, editors. TRP ion channel function in sensory transduction and cellular signaling cascades. Boca Raton, FL: Frontiers in Neuroscience; 2007.

74 Wang-Sheng C, Jie A, Jian-Jun L, Lan H, Zeng-Bao X, Chang-Qing L. Piperine attenuates lipopolysaccharide (LPS)-induced inflammatory responses in BV2 microglia. Int Immunopharmacol. 2017;42:44-8.

75 Okumura Y, Narukawa M, Iwasaki Y, Ishikawa A, Matsuda H, Yoshikawa M, et al. Activation of TRPV1 and TRPA1 by black pepper components. Biosci Biotechnol Biochem. 2010;74(5):1068-72.

76 Dong Y, Yin Y, Vu S, Yang F, Yarov-Yarovoy $\mathrm{V}$, Tian Y, et al. A distinct structural mechanism underlies TRPV1 activation by piperine. Biochem Biophys Res Commun. 2019;516(2): 365-72.

77 Korenori Y, Tanigawa S, Kumamoto T, Qin S, Daikoku Y, Miyamori K, et al. Modulation of Nrf2/Keap1 system by Wasabi 6-methylthiohexyl isothiocyanate in ARE-mediated NQO1 expression. Mol Nutr Food Res. 2013;57(5): 854-64.

78 Terada Y, Masuda H, Watanabe T. Structureactivity relationship study on isothiocyanates: comparison of TRPA1-activating ability between allyl isothiocyanate and specific flavor components of wasabi, horseradish, and white mustard. J Nat Prod. 2015;78(8):193741.
Foods with Antioxidant and TRP

Activities in COVID-19
Int Arch Allergy Immunol 2021;182:489-495 DOI: $10.1159 / 000513538$ 